\title{
On the Tropical Atlantic SST warm bias in the Kiel Climate Model
}

\author{
Sebastian Wahl · Mojib Latif · Wonsun Park • \\ Noel Keenlyside
}

Received: 6 July 2009/ Accepted: 15 October 2009

(C) Springer-Verlag 2009

\begin{abstract}
Most of the current coupled general circulation models show a strong warm bias in the eastern Tropical Atlantic. In this paper, various sensitivity experiments with the Kiel Climate Model (KCM) are described. A largely reduced warm bias and an improved seasonal cycle in the eastern Tropical Atlantic are simulated in one particular version of KCM. By comparing the stable and well-tested standard version with the sensitivity experiments and the modified version, mechanisms contributing to the reduction of the eastern Atlantic warm bias are identified and compared to what has been proposed in literature. The error in the spring and early summer zonal winds associated with erroneous zonal precipitation seems to be the key mechanism, and large-scale coupled ocean-atmosphere feedbacks play an important role in reducing the warm bias. Improved winds in boreal spring cause the summer cooling in the eastern Tropical Atlantic (ETA) via shoaling of the thermocline and increased upwelling, and hence reduced sea surface temperature (SST). Reduced SSTs in the summer suppress convection and favor the development of lowlevel cloud cover in the ETA region. Subsurface ocean structure is shown to be improved, and potentially influences the development of the bias. The strong warm bias along the southeastern coastline is related to underestimation of low-level cloud cover and the associated overestimation of surface shortwave radiation in the same region. Therefore, in addition to the primarily wind forced
\end{abstract}

S. Wahl $(\bowtie) \cdot$ M. Latif · W. Park · N. Keenlyside

Leibniz Institute of Marine Sciences, Düsternbrooker Weg 20,

24105 Kiel, Germany

e-mail:swahl@ifm-geomar.de response at the equator both changes in surface shortwave radiation and outgoing longwave radiation contribute significantly to reduction of the warm bias from summer to fall.

Keywords Tropical Atlantic - SST warm bias . Climate modeling $\cdot$ Seasonal cycle $\cdot$ Kiel Climate Model . $\mathrm{KCM}$

\section{Introduction}

It has been a long standing problem for coupled general circulation models (CGCMs) to correctly simulate Tropical Atlantic (TA) climate. The most pronounced error in basically all of the state-of-the-art CGCMs is the strong warm bias in sea surface temperature (SST) in the eastern Tropical Atlantic (ETA) which leads to a reversal of the SST gradient along the equator (Davey et al. 2002; Fig. 2 in Richter and Xie 2008). A similar warm bias is simulated in the Tropical Pacific both north and south of the equator, and in the eastern South Tropical Indian Ocean. However, the bias is particularly important in the Tropical Atlantic given its small basin size and the reversal of gradient. The warm bias causes major problems in simulating present and future climate in the Tropical Atlantic, specifically precipitation. For example, ETA SST is important for the correct representation and forecast of the African Monsoon on seasonal and decadal timescales today as well as under future climate scenarios (e.g. Hulme et al. 2001).

In the Tropical Atlantic, the annual cycle is the dominant signal in SST. A good overview on the mechanisms associated with the annual cycle in the Tropical Atlantic is given by Chang et al. (2007). The most up-to-date 
study on the causes of Tropical Atlantic biases in CGCM has recently been published by Richter and Xie (2008). They show by comparing AMIP-type (Atmospheric Model Intercomparison Project, Gates 1992) with CMIP (Coupled Model Intercomparison Project, based on IPCCAR4 model output) experiments that a westerly surface wind stress bias in the central and western Tropical Atlantic already exists in the AGCMs, but only in boreal spring. This is due to anomalously high (low) sea-level pressure in the western (eastern) Equatorial Atlantic, which Richter and Xie (2008) attribute to deficient (excessive) precipitation over tropical South America (Africa). These biases are amplified in the coupled model simulations. The westerly wind stress bias in spring causes the thermocline to be too deep in the eastern Equatorial Atlantic preventing the development of a summer cold tongue. Chang et al. (2008) find similar results with CCSM3 (Community Climate System Model, version 3, Collins et al. 2006). They argue that the westerly bias in zonal wind stress in the Tropical Atlantic in boreal spring originates from a large precipitation bias in the eastern Amazon region. The precipitation bias is attributed to the inability of the AGCMs to correctly simulate the amount of convective precipitation over land.

SST biases in the TA region also cause errors in atmospheric circulation since strong ocean-atmosphere coupling is present in the Tropics. Stockdale et al. (2006) find that the interhemispheric SST gradient is important for MAM (March-April-May) precipitation in northeastern Brazil, while equatorial SST and the east-west SST gradient at the equator influences West African rainfall. Thus the circulation biases in the AGCMs when run with prescribed observed SSTs may be further amplified through ocean-atmosphere feedbacks in coupled mode (Richter and Xie 2008).

Another source of error is the representation of low clouds in the southeastern part of the Tropical Atlantic and Pacific, in which also coupled feedbacks play an important role. While in the Pacific this problem has received attention more than 10 years ago (e.g. Gordon et al. 2000; Ma et al. 1996; Nigam 1997; Yu and Mechoso 1999), only recently work has been done on southeastern Tropical Atlantic low cloud representation in CGCMs. Huang et al. (2007) used a set of ensemble hindcasts from CFS (NCEP coupled forecast system, Saha et al. 2006) to analyze the warm bias in the southeastern Tropical Atlantic which rapidly grows in boreal summer and peaks in NovemberDecember. They attribute the bias to excessive shortwave (SW) radiation reaching the surface which in turn causes the model to simulate too little low cloud cover in the region due to changes in lower tropospheric stability. $\mathrm{Hu}$ et al. (2008) find as well that the radiative flux directly affects the simulated SST. They show that the model produces too little low and too much high clouds amplified by a biased atmospheric stratification which might be responsible for a warm bias of up to $3 \mathrm{~K}$ near the southeastern boundary. It has to be pointed out that the NCEP-CFS has a relatively high resolution in the lower troposphere (20 sigma levels below $650 \mathrm{hPa}$ ) so there is little hope that any of the current coarse resolution climate models can realistically simulate Atlantic low clouds and associated feedbacks.

In summary two main sources for the SST bias in the Tropical Atlantic due to atmospheric forcing seem to dominate the discussion. First, the westerly wind stress bias in AGCMs especially in spring that prevents summer cooling in the eastern Tropical Atlantic. Second, a local low cloud bias that causes excessive shortwave radiation and hence SST warming in the southeastern Tropical Atlantic. While all of the above mentioned studies attribute TA SST bias to biases in atmospheric physics, there are also few studies attributing the source of error to the inability of the ocean model to simulate the observed strength of coastal upwelling (Large and Danabasoglu 2006). It should be mentioned in this context that many ocean components of CGCMs have relatively poor horizontal and/or vertical resolution so that simply enhanced ocean model resolution may help to improve the simulation of coastal upwelling and thus SST. One study attributes the bias to poorly resolved mesoscale variability (Seo et al. 2006). Increased entrainment efficiency at the bottom of the mixed layer largely improved thermocline structure and SST bias in coupled model simulations analyzed by Hazeleger and Haarsma (2005). More recently Lee and Wang (2008) speculate using results from a simplified coupled model that a strong meridional dipole mode (e.g. Servain 1991) could possibly contribute to the development of the warm bias. Breugem et al. (2008) attribute a significant part of the eastern and southeastern Tropical Atlantic SST warm bias to the formation of spurious barrier layers (BLs). BLs prevent surface cooling through strong salinity stratification and a subsurface temperature maximum (see Fig. 1 in Breugem et al. 2008). Together with low sea surface salinities due to a southward displacement of the ITCZ in boreal spring and summer a positive feedback "BL-SST-ITCZ" mechanism enhances erroneous SST in the eastern TA.

The aim of this study is to assess the mechanisms mentioned above by analysis of different setups of the Kiel Climate Model (KCM) and evaluate their importance. The paper is structured as follows. Section 2 gives a short overview of the coupled model used and the sensitivity experiments that have been performed as well as the modifications applied in the model. The mean response in the atmosphere and ocean circulation is described in Sect. 3. The last section provides the main conclusions. 


\section{Model and data}

The basis for this study is the Kiel Climate Model (KCM, Park et al. 2009), which has been used to study long-term internal variability (Park and Latif 2008) as well as forced variability (Latif et al. 2009). The model uses ECHAM5 (Roeckner et al. 2003) as the atmospheric component. In the current configuration the atmospheric component uses T31 horizontal resolution (approximately $3.75^{\circ}$ by $3.75^{\circ}$ ) with 19 vertical levels up to $10 \mathrm{hPa}$. The ocean model component is the Nucleus for European Modeling of the Ocean (NEMO; Madec 2008), and is coupled to ECHAM5 via the Ocean Atmosphere Sea Ice Soil version 3 (OASIS3, Valcke et al. 2006). Ocean resolution is $2^{\circ}$ with an equatorial latitudinal refinement of $0.5^{\circ}$. In the Tropical Pacific the model realistically reproduces the mean state, El Niño/ Southern Oscillation (ENSO) and the annual cycle both in strength and frequency (Park et al. 2009). In the Tropical Atlantic a strong warm bias in the ETA SST is present (Fig. 1), as common to basically all state-of-the-art CGCMs (see Introduction). More detailed information about the model setup and its general performance can be found in Park et al. (2009).

The reference run (REF) is essentially the same as the one described in Park et al. (2009) except for a few minor model modifications that are not relevant for the problems discussed in this paper. In addition a set of experiments (Table 1) were performed, which can be separated into three type of setups: The RAD, WIND4, WIND10 and FLX experiments contain "artifical" changes in the REF configuration to identify the effects of incoming shortwave radiation, wind stress and correct mean ocean state, while in the modified version of KCM (MOD) experiment modifications within the model parameterizations are applied that are found to be important as descried later. The last group contains two uncoupled experiments (REFUC and MODUC).

In the radiation (RAD) experiment the SW radiation penetrating into the ocean is reduced by $30 \%$ and $15 \%$ at certain grid points along the coast (Fig. 2). This experiment is used to assess the effect of excessive surface radiation at the surface on the SST bias in the southeastern Tropical Atlantic. The values are chosen at those grid points where the mean SST bias is largest and roughly correspond to a reduction in surface shortwave radiation of $40-80 \mathrm{~W} / \mathrm{m}^{2}$. These values are in the range of excessive shortwave radiation in the southeastern Tropical Atlantic as suggested by $\mathrm{Hu}$ et al. (2008). We note that this approach is somewhat inconsistent with previous result, which show that the biases in low cloud and surface radiation extend further off the coast (Hu et al. 2008; Fig. 3c). However, it allows us to quantify the direct impact of excessive shortwave radiation in the region where the warm bias is strongest.

Richter and Xie (2008) and Chang et al. (2008) claim the westerly wind stress bias in the western Tropical Atlantic to have strong influence on the development of the SST bias. To evaluate the importance of this mechanism a run with climatological wind stress between $4^{\circ} \mathrm{S}$ and $4^{\circ} \mathrm{N}$ in the Atlantic has been performed and is referred to as WIND4. Towards the north and south a linear transition between the climatological wind stress and the model generated wind stress is applied to avoid spurious effects due to a rapid change in wind stress along $4^{\circ} \mathrm{S}$ and $4^{\circ} \mathrm{N}$. The wind stress climatology has been calculated from monthly NCEP-NCAR Reanalysis data from 1950 to 2004, and is linearly interpolated online onto the corresponding time step during the model run. The same experiment has been repeated with climatological wind stress merged into the model between $10^{\circ} \mathrm{S}$ and $10^{\circ} \mathrm{N}$, and is referred to as WIND10.
Fig. 1 Mean SST bias towards observed SST in the Tropical Atlantic in the REF experiment

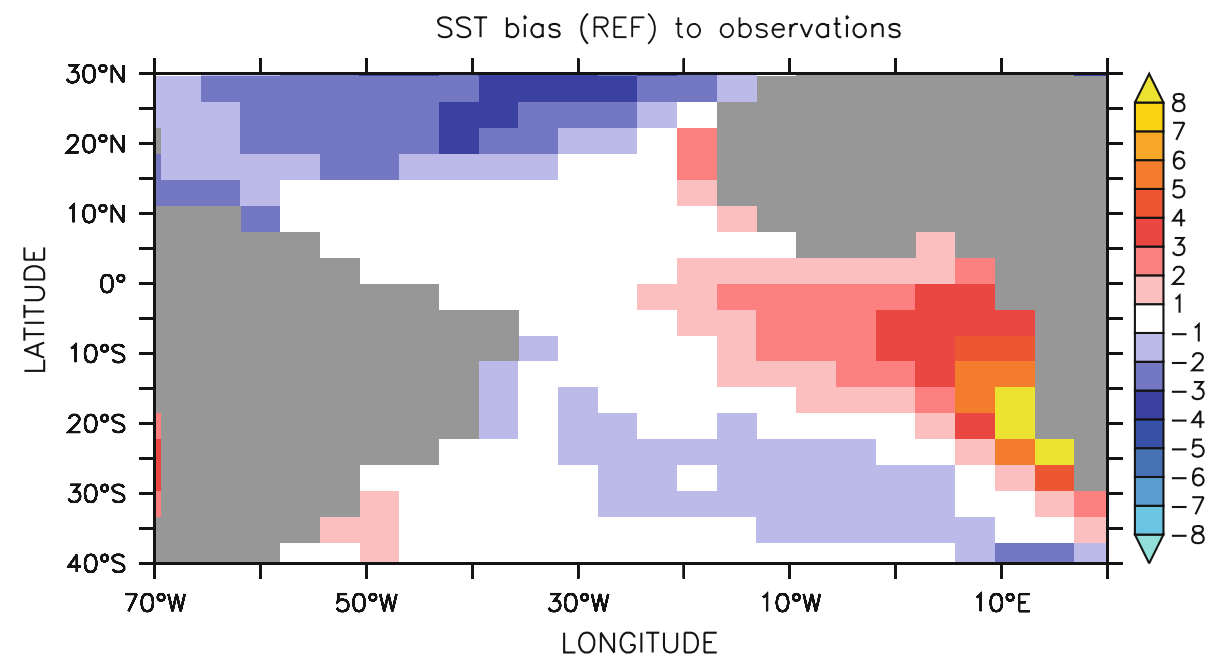


Table 1 Configurations of the Kiel Climate Model used in this study

\begin{tabular}{lll}
\hline EXPID & Years & Modifications with respect to REF experiment \\
\hline REF & 120 & REF experiment, see Park et al. (2009) \\
WIND4 & 50 & Climatological wind forcing between $4^{\circ} \mathrm{S}$ and $4^{\circ} \mathrm{N}$ in the Atlantic \\
WIND10 & 50 & Climatological wind forcing between $10^{\circ} \mathrm{S}$ and $10^{\circ} \mathrm{N}$ in the Atlantic \\
RAD & 50 & Modified SW radiation in SE Atlantic as depicted in Fig. 2 \\
FLX & 120 & Flux corrected version of KCM \\
MOD & 120 & Modified parameters as described in Sect. 2 \\
REFUC & 20 & Uncoupled version of REF \\
MODUC & 20 & Uncoupled version of MOD \\
OCE & 45 & Uncoupled ocean run \\
\hline
\end{tabular}

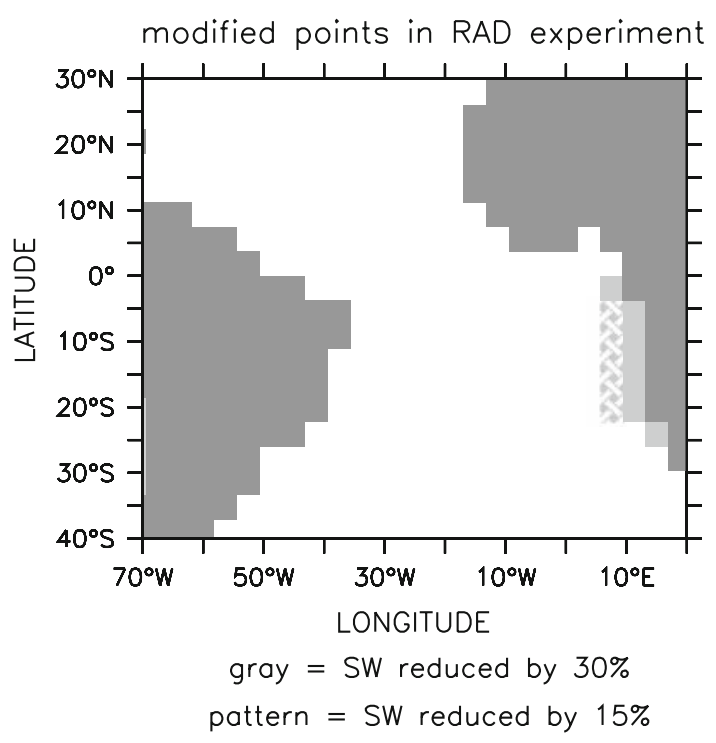

Fig. 2 Model grid points where modifications in the RAD run are applied as denoted on the figure, for details see text

Flux corrections are often used to overcome the problems associated with model biases, but do not necessarily fix subsurface errors in the ocean. To evaluate subsurface impact on atmospheric circulation that "sees" the correct SST climatology, a run with flux corrections has been performed (FLX). To calculate the flux-corrections a 50 year run with restoring towards climatological SSTs between approximately $40^{\circ} \mathrm{S}$ and $40^{\circ} \mathrm{N}$ has been performed. North (south) of $40^{\circ} \mathrm{N}(\mathrm{S})$ restoring is linearly reduced towards the north (south). The last 10 years of this run have been used to calculate net surface heat flux climatology which has been applied on a daily basis in the FLX run.

The modified version of KCM (MOD) contains modifications in the physical parameterizations of the atmospheric model that mainly affect the turbulent surface transfer of heat and moisture at the ocean surface. Generally, the surface flux of a variable is controlled by turbulent fluxes, which must be parameterized in AGCMs using bulk parameterizations because of the small scale nature of turbulent processes. The turbulent fluxes of heat and moisture at the surface mainly depend on the roughness of the surface, horizontal wind speed and atmospheric stratification above the sea surface. The turbulent flux of a variable $\mathrm{X}$ is obtained from the bulk transfer relation (Roeckner et al. 2003):

$\overline{(\omega / X \prime)} S=-C_{x}\left|\mathrm{~V}_{L}\right|\left(X_{L}-X_{S}\right)$

where $\mathrm{C} \chi$ is the transfer coefficient. The subscripts $L$ and $S$ refer to values at the lowest model level and the surface layer, respectively, and $V_{L}$ is the horizontal wind vector at level $L$. The transfer coefficient for moisture and heat can be expressed as

$C_{q h}=C_{N} f_{q h}$

where $C_{N}$ is the neutral transfer coefficient and $f$ the stability function representing the ratio of $C_{q h}$ to the respective value under neutral conditions (Roeckner et al. 2003). The stability function $\mathrm{f}$ is defined separately for land, ice and water surfaces and stable and unstable conditions, respectively. Following Miller et al. (1992), in unstable conditions over sea an empirical interpolation is used between the free convection limit and the neutral approximation is used to ensure that free convection conditions prevail:

$f=\left(1+C_{R}^{1.25}\right)^{1 / 1.25}$

$C_{R}=\beta \frac{\left(\Delta \Theta_{\mathrm{v}}\right)^{1 / 3}}{C_{N}\left|\mathrm{~V}_{L}\right|}$

$\Theta_{\mathrm{v}}$ denotes the virtual potential temperature difference between the surface and the lowest model level L. In the MOD version mainly the parameter $\beta$ in Eq. 4 is increased. It hence increases the transfer coefficient of heat and moisture being most effective at low wind speeds and large instabilities (i.e. large $\Theta_{\mathrm{v}}$ ). Over land the transfer parameter $\mathrm{f}$ depends on surface roughness and vegetation index, and has not been changed. 
(a) SST (C)
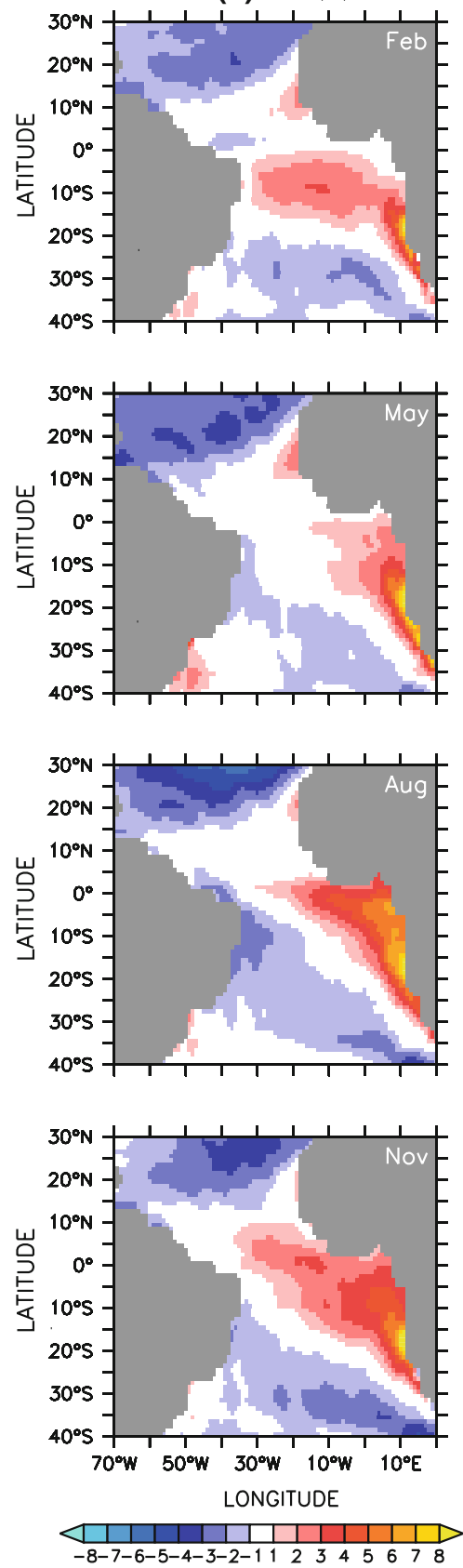

(b) $10 \mathrm{~m}$ Wind $(\mathrm{m} / \mathrm{s})$
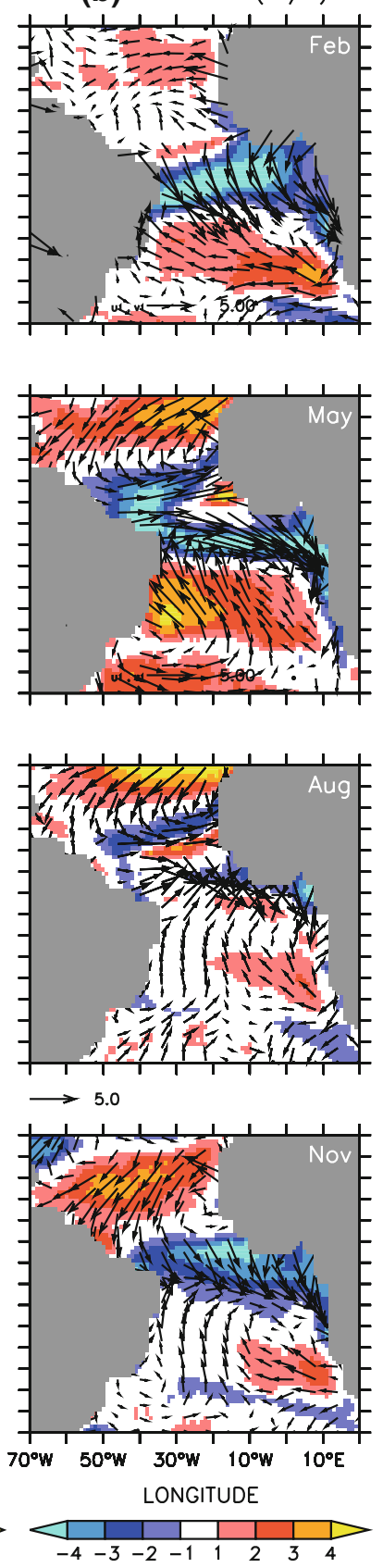

(c) low Cloud (\%)
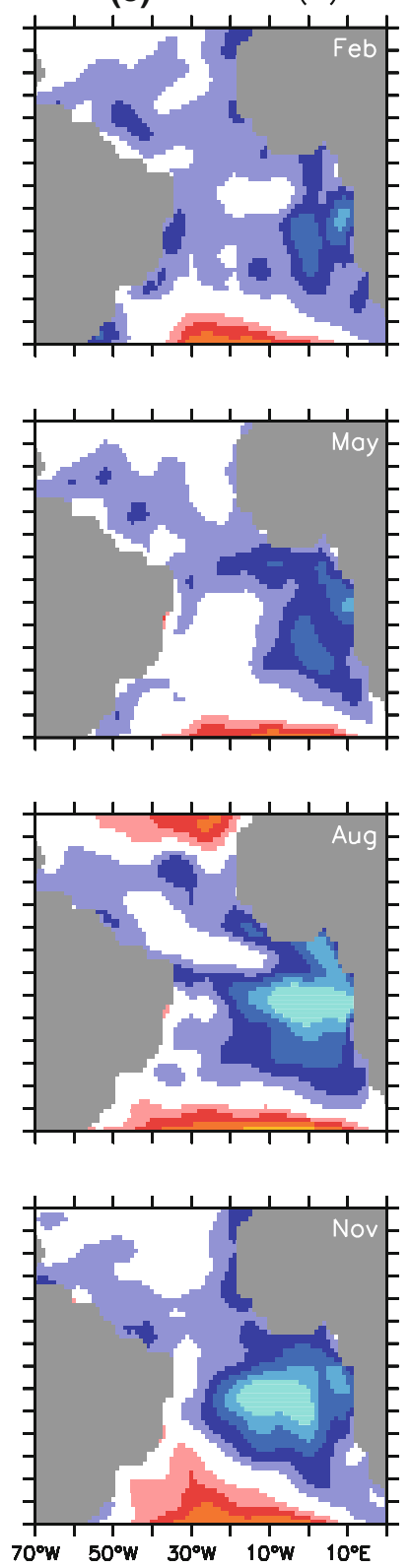

LONGITUDE

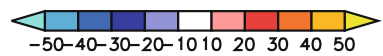

(d) precip (mm/day)
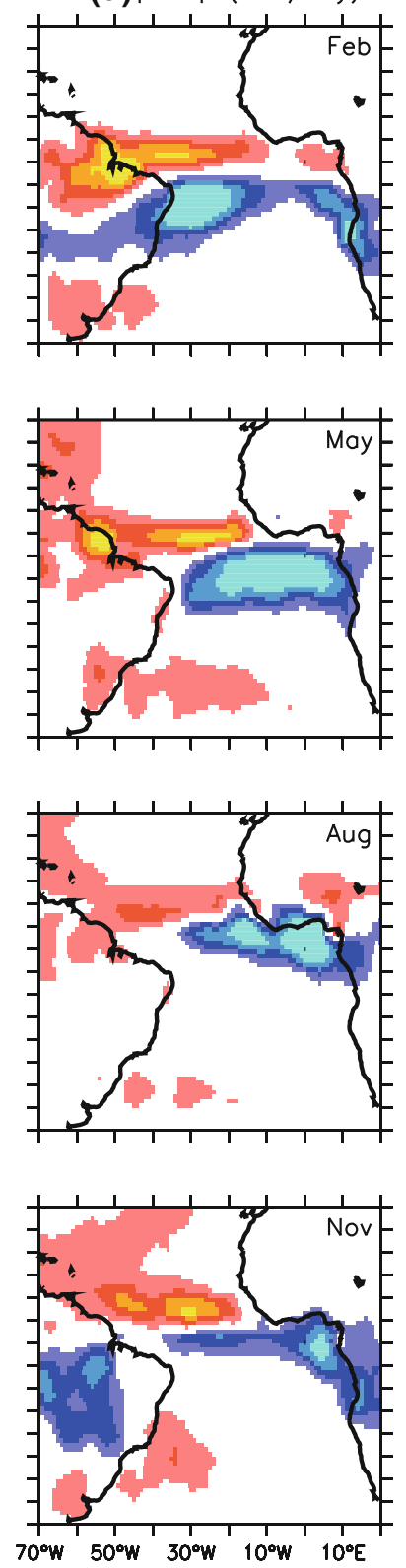

LONGITUDE

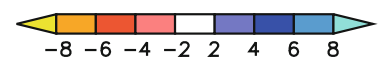

Fig. 3 February (top), May (second row), August (third row) and November (bottom) bias of SST (a), $10 \mathrm{~m}$ wind (b), low cloud cover (c) and precipitation (d) towards observations in the REF experiment in the Tropical Atlantic. The shading in $\mathbf{b}$ shows the bias in total windspeed. The length of a standard array is indicated below the figure in the third row. Please note the reversed colorbar in $\mathbf{d}$
The third group of experiments consists of three uncoupled experiments. Two AMIP-type experiments have been performed both with MOD and REF configuration which will be referred to as MOD uncoupled (MODUC) and REF uncoupled (REFUC), respectively. The third experiment is an uncoupled ocean run (OCE) covering the period 1958-2002. The atmospheric forcing at $10 \mathrm{~m}$ height is provided by the CORE dataset by Large and Yeager
(2004). All required atmosphere-ocean fluxes are then computed via bulk formulae (Kara et al. 2000). Note that a different version of the ocean model (e.g. advection scheme and thus different parameters) is used in the OCE experiment. As the OCE experiment is only used to evaluate the mean state and the mean annual cycle, it is believed that the differences in the model versions do not compromise the results. If not stated otherwise, 20 years 
from the end of a run are used for analysis. For the runs which are only 50 years or shorter the last 10 years are used.

Observational SST is taken from the NCEP/NCAR reanalysis (Kalnay et al. 1996) covering the period from 1950 to 2004. Observed high and low cloud cover compared to model output in different layers is taken from International Satellite Cloud Climatology Project (ISCCP, Rossow and Schiffer 1991) from year 1984 to 2000. As shown in Fig. 4 of Rossow and Schiffer (1991) all clouds detected below $680 \mathrm{hPa}$ are regarded as low clouds in the ISCCP dataset. To calculate total cloud cover below $680 \mathrm{hPa}$ from the model data, assumptions about the vertical overlap have to be made. In this study clouds are assumed not to be overlapped at all, i.e. the sum of the cloud cover in all model layers below $680 \mathrm{hPa}$ is taken. Other methods of calculation of total cloud cover from several layers have been tested as well. In all methods the principle bias patterns towards ISCCP did not change. Observed precipitation is taken from the dataset by Xie and Arkin (1997) which extends from 1979 to 2006. Zonal and meridional wind components as well as total windspeed are compared to 6 years (2000-2005) of high resolution quickscat observations (Graf et al. 1998). To compare subsurface temperature and salinity the Simple Ocean Data Assimilation (SODA version 1.4.2, Carton and Giese 2008) reanalysis dataset from 1980 to 1999 is used. Although observational data used in this study do not cover identical periods, they are long enough to provide a robust estimate of the annual cycle and the differences introduced by this are small in comparison to the coupled model biases described here.

\section{Mean state and seasonal cycle in the Tropical Atlantic}

The mean bias in the REF experiment in SST, $10 \mathrm{~m}$ winds, low cloud and precipitation in the Tropical and Subtropical Atlantic for four different months is displayed in Fig. 3. The SST bias is smallest in May at the equator, rapidly increases towards summer and extends through boreal fall and winter. The coastal SST bias off southwestern Africa is strongest near $20^{\circ} \mathrm{S}$ and exists in all seasons with much smaller seasonal variation. We note also the cold biases, which surround the warm bias. Along the equator a north to northwesterly windstress bias is found in boreal fall and winter. In boreal spring a strong westerly bias is present along the equator. The seasonal cycle of the bias in low cloud cover along the southeastern coast follows the seasonal cycle of the SST bias, i.e. strongest underestimation of low cloud occurs at the same as the SST bias is largest that is consistent with Huang et al. (2007) and Hu et al.
(2008). In the central Subtropical Atlantic SST seems to be insensitive to the large underestimation of low clouds that peaks in boreal summer to fall. The precipitation bias clearly shows the southward shift of the ITCZ. It is most pronounced in the eastern Tropical Atlantic where excessive precipitation is found almost all year round.

The bias patterns just described are in broad accordance with those found in other coarse resolution CGCMs (Davey et al. 2002; Richter and Xie 2008). The sensitivity of KCM to different processes affecting the development of the strong warm bias is discussed in the following by means of sensitivity experiments.

\subsection{Sensitivity to local winds and surface radiation}

Figure 4 shows the SST difference in the RAD, WIND4 and WIND10 experiments relative to that in the reference run. Reduction of SW radiation reaching the surface in the RAD experiment has a large impact with local cooling of more than $2.5 \mathrm{~K}$ (Fig. 4a). In the WIND4 experiment the differences in mean SST towards the reference experiment (Fig. 4b) are primarily found at the equator in the eastern part of the basin. Differences to the REF experiment are small along the southeastern coast and might indicate the southward spread of SST patterns through coastal waves (Florenchie et al. 2003; Polo et al. 2008). A stronger cooling pattern is found in the eastern Equatorial Atlantic in the WIND10 experiment primarily south of the equator as well as down the southeastern coast. Especially the cooling along the southeastern coast is stronger. It shows that off-equatorial winds are important for the development of the seasonal cycle of the bias (not shown) and the mean gradient along the equator (Fig. 5). It is consistent with Ding et al. (2009) who show that off-equatorial waves at $4^{\circ} \mathrm{S}$ and $4^{\circ} \mathrm{N}$ are necessary to explain the correct seasonal cycle of surface currents along the equator. Stronger southerly winds between $4^{\circ} \mathrm{S}$ and $10^{\circ} \mathrm{S}$ that can cause intensified coastal upwelling might also play a role. In terms of the geographical distribution of the SST bias the excessive surface SW radiation in the southeastern Atlantic can be an important factor for the development of the SST bias in the eastern Tropical Atlantic. To assess the temporal development of the bias in these two experiments, Fig. 4 has been compared to similar figures for years 5-10 and 80-100 of the same runs (not shown). Comparing those figures shows that the realistic winds in the WIND4 and WIND10 experiment have an immediate effect on the bias pattern, i.e. the pattern seen in Fig. $4 \mathrm{~b}$ does not change much over time. For the RAD experiment the cooling grows continuously over time and seems to stabilize with a pattern very similar to the one shown in Fig. 4a. This is attributed to the fact that energy is continuously removed without any compensation from the coupled system by the 
(a) RAD - REF

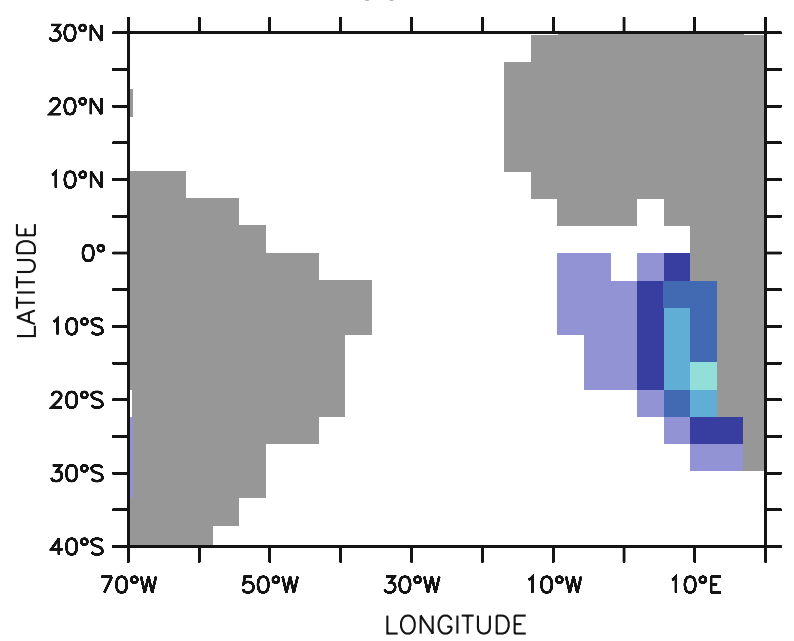

(b) WIND4 - REF

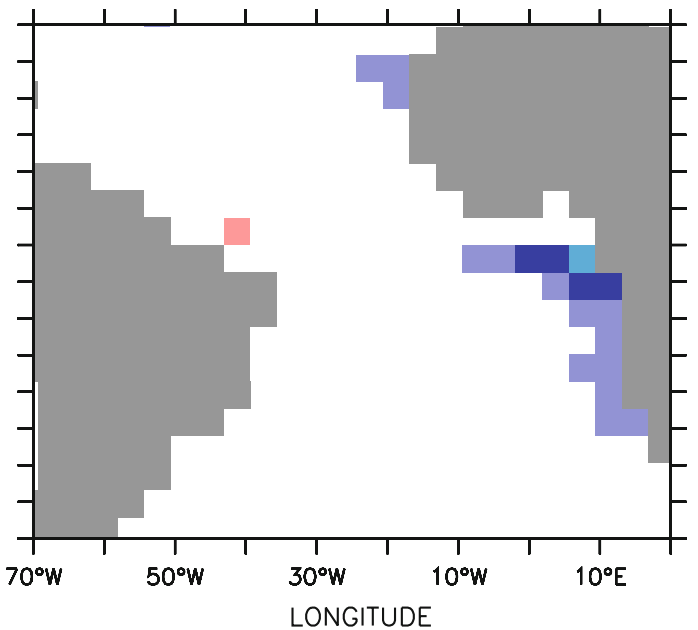

(c) WIND10 - REF

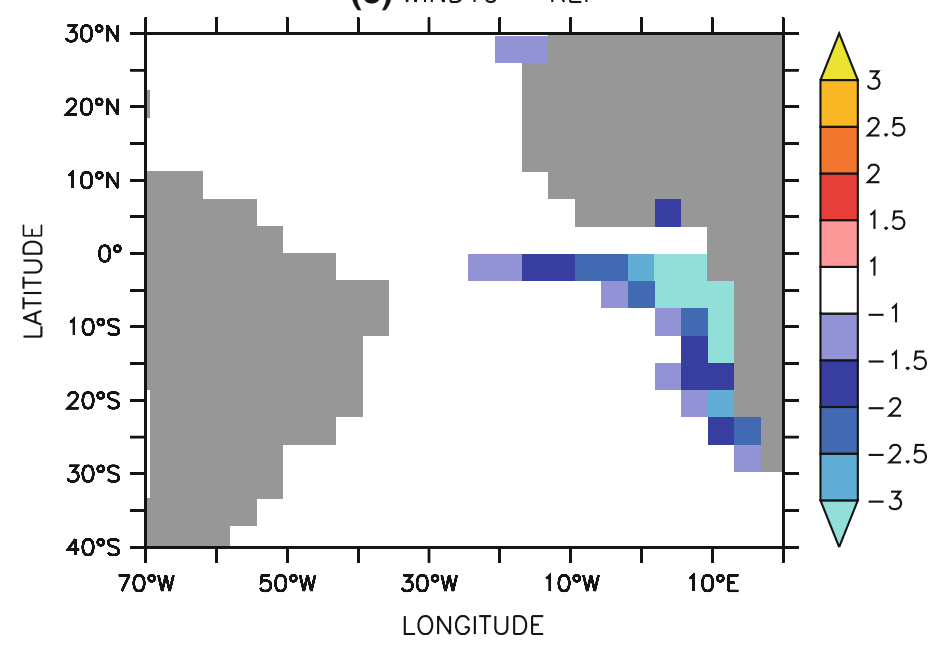

Fig. 4 SST deviation towards REF run in RAD (a), WIND4 (b) and WIND10 experiment

artifical reduction of the shortwave radiation penetrating into the ocean.

The gradient along the equator for the three sensitivity experiments is shown in Fig. 5. All of the RAD, WIND4 and WIND10 experiment show a significant improvement in the eastern half of the basin, with the latter being very close to the observed gradient. However, biases remain in all experiments. We note that realistic winds directly along the equator (WIND4 experiment) are not enough to produce a realistic equatorial SST gradient. Only if realistic winds between $10^{\circ} \mathrm{S}$ and $10^{\circ} \mathrm{N}$ (WIND10 experiment) are provided, the model produces a gradient very close to observations indicating that realistic winds off the equator seem to be an important contributor towards the mean gradient (see also Sect. 3c). Our results are in agreement with both the results from Huang et al. (2007) and Richter and Xie (2008). Huang et al. (2007) attribute a large portion of the bias to excessive surface SW radiation, while

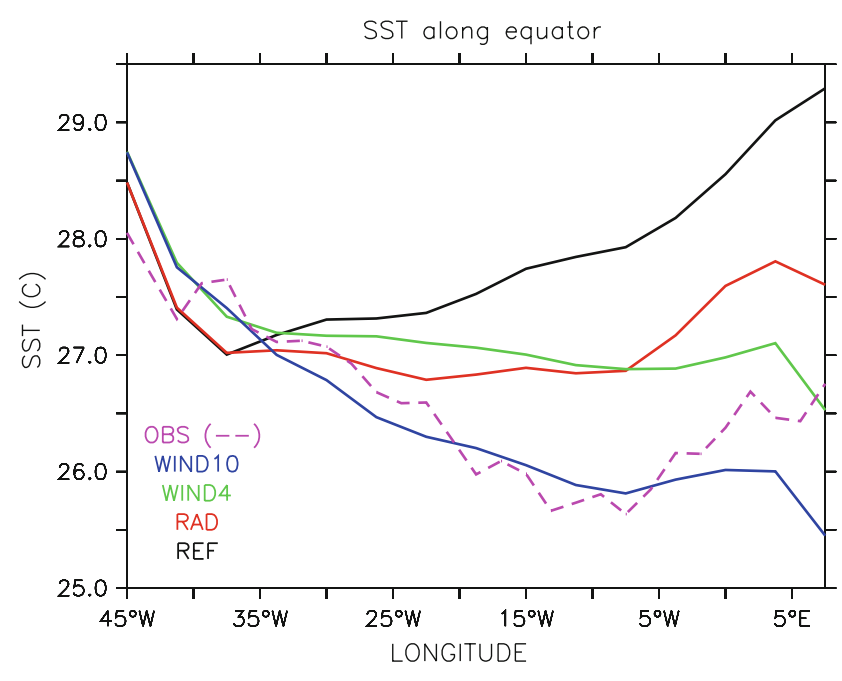

Fig. 5 SST along the equator in different sensitivity experiments as indicated on the figure as well as observed SST 
Richter and Xie (2008) claim the weaker-than-observed easterlies along the equator to be important for the development of the bias. Comparing the changes in zonal wind stress in the Tropical Atlantic for the REF and RAD experiments reveals that a reduced bias in the southeastern Tropical Atlantic in the RAD experiments strengthens the equatorial easterlies (not shown). This suggests a significant influence of processes in the southeastern Tropical Atlantic onto equatorial circulation as mentioned by $\mathrm{Hu}$ and Huang (2007), while the WIND4 and WIND10 experiment suggest a significant impact of the equatorial biases onto the southeastern coastal warm bias. The SST errors along the equator and the southeastern coast therefore seem to be coupled. However, the processes that lead to the reduction of the bias are different in the southeastern Atlantic and along the equator. Along the southeastern coast the reduction in SST results in an increase in cloud cover of up to $20 \%$ from boreal summer to fall in the RAD and WIND10 experiment. At the equator, the reduction in eastern Atlantic SST goes along with changes in convective activity similar to the changes described in the following section. Consistent with the small reduction of the SST bias directly along the equator in the RAD experiment (Fig. 4a), differences in convective activity in the equatorial area are smaller between the RAD and REF than between the WIND10 and REF experiment, respectively (Figures not shown).

To quantify the overall impact of the southeastern surface radiation bias, another sensitivity experiment, which has the surface radiation bias corrected further off the coast as well, would be helpful. The modifications applied to the atmosphere also cause significant changes in the mean ocean state. These will be discussed together with the results from the MOD experiment at the end of the following section.

\subsection{Atmospheric and surface response in the MOD experiment}

In the experiments discussed above artifical modifications have been applied to KCM to further understand the causes of the bias and compare to what has been discussed in literature. In the MOD experiment modifications are in the parameters concerning the parameterization of air-sea exchange as described in Sect. 2. The most striking difference between REF and MOD is the strong reduction of the warm bias that exceeds $4 \mathrm{~K}$ in the eastern part of the basin (Fig. 6a) that is about $8 \mathrm{~K}$ in REF (Fig. 1). Figure 6b shows clearly that the reduction in MOD relative to REF is most pronounced in those areas where the largest bias in REF is found. The improvements also project onto the gradient along the equator (Fig. 6c). Further the reduction in the bias in MOD is stronger compared to the reduction found in the sensitivity experiments described above. The development of the eastern Tropical Atlantic warm bias in REF shows a pronounced seasonality (Fig. 7a). Along the equator the warm bias starts to develop around May, peaks in July-August-September and weakens towards December. In MOD the warm bias is considerably reduced (Fig. 7b). A weak warm bias, however, is still present in summer. At the same time a slight cold bias develops in the western part which is due to the general cooling of approximately $1 \mathrm{~K}$ over the whole Tropical Atlantic. As shown by Richter and Xie (2008) zonal winds along the equator in spring are crucial for summer cooling, and hence the reduction of an eastern Equatorial Atlantic model warm bias. The zonal wind stress difference in MAM between MOD and REF is shown in Fig. 8a. The westerly bias is reduced by more than $0.02 \mathrm{~N} / \mathrm{m}^{2}$. It corresponds to a change from a westerly component in REF to a weak easterly component in the zonal wind stress in the central Equatorial Atlantic in MOD. The strengthening of the MAM easterlies is connected with increased precipitation west of $20^{\circ} \mathrm{W}$ peaking off the eastern coast of Brazil (Fig. 8b). This, however, is inconsistent with observations, which indicates deficient precipitation over northeastern Brazil in KCM and not over the ocean. As convection is present west of $20^{\circ} \mathrm{W}$ in both the REF and MOD experiment only minor differences in cloud cover in the upper levels and hence outgoing longwave radiation (OLR, Fig. 8c) occurs. Simultaneously, precipitation is reduced in the Gulf of Guinea. Even though the location of the precipitation increase is not correct it sets up a pressure gradient that enhances easterly flow along the equator, basically corresponding to an intensified Atlantic Walker Circulation. Downward motion is enhanced in the eastern and upward motion enhanced in the western part of the Equatorial Atlantic in response to enhanced (reduced) convection in the western (eastern) Equatorial Atlantic. This is confirmed by seasonally resolved differences in vertical velocity along the equator as well as upper level zonal wind speeds (not shown). Comparing absolute values of SST between MOD and REF shows that in REF SST in the eastern Tropical Atlantic is roughly $28^{\circ} \mathrm{C}$ or above all year round, while in MOD no SSTs above $28^{\circ} \mathrm{C}$ are simulated. According to e.g. Fu et al. (1994) a SST of $28^{\circ} \mathrm{C}$ is believed to be a critical value for deep convection to develop and possibly explains the reduction in convective activity over the eastern Tropical Atlantic in MOD. This is supported by reduced amount of high clouds (as analyzed on the $300 \mathrm{hPa}$ level) spreading in the upper troposphere due to convective towers (not shown). A reduction in cloud cover at the model levels in the upper troposphere as well as drying of the upper atmospheric layers increases the amount of outgoing longwave radiation (OLR, Fig. 8c) via the water vapor feedback. An increased amount of OLR 
(a) MOD: SST bias to OBS

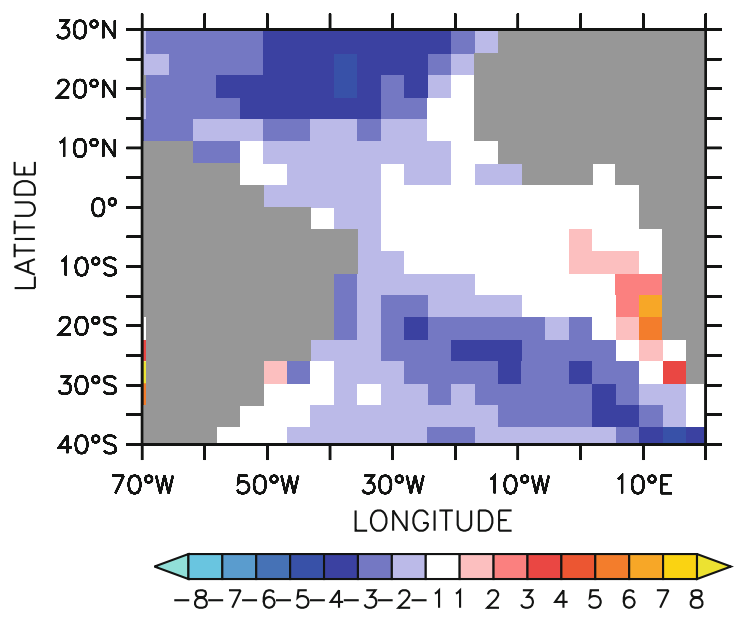

(b) SST difference MOD-REF

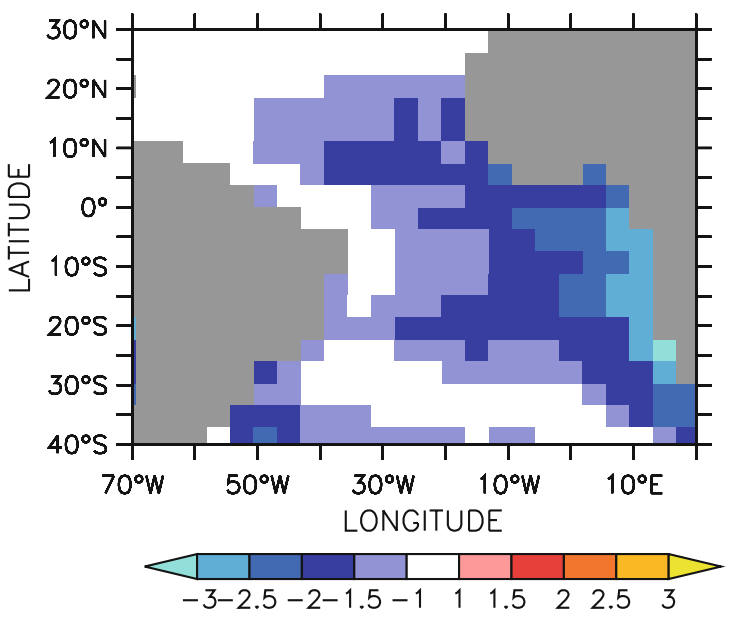

(c) SST along equator

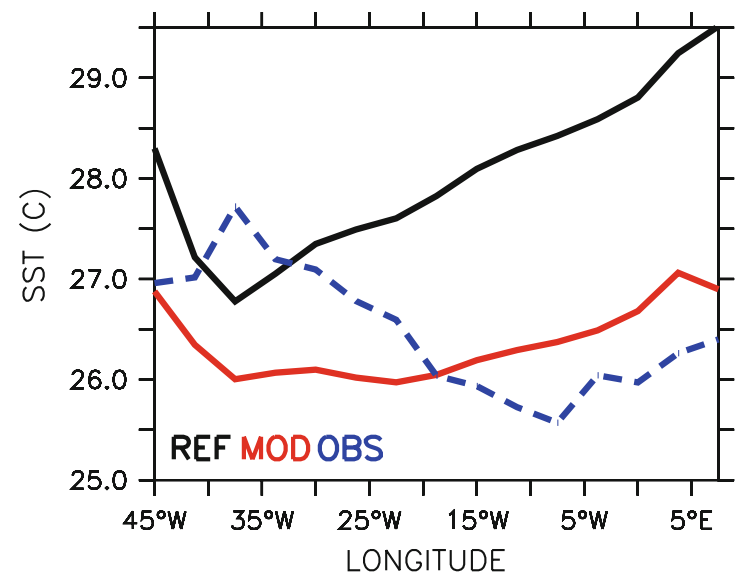

Fig. 6 a SST bias to observed SST in the MOD experiment; b SST difference of MOD to REF experiment; $\mathbf{c}$ SST gradient along the equator in MOD, REF and observations

contributes to cooling of the atmospheric column that may indirectly contribute to SST cooling. In those areas in the Gulf of Guinea where low cloud cover does not increase (Fig. 8d) the increased amount of OLR is balanced by more shortwave radiation reaching the surface. As indicated in Fig. 8d, increase of low cloud cover is most pronounced further to the south between $10^{\circ} \mathrm{S}$ and $20^{\circ} \mathrm{S}$. This is consistent with $\mathrm{Hu}$ et al. (2008) claiming that the excessive surface SW radiation due to underestimation of low cloud has a significant impact on the SST bias in the southeastern Tropical Atlantic. SST and the evolution of low cloud cover are tightly coupled and exhibit a positive feedback. Increase of low cloud cover is hence not the driver of the reduction of the SST but acts as an amplifier in the positive feedback once the SST is cold enough to support the development of low clouds. This is supported by comparing low cloud cover of the uncoupled version of the reference run (REFUC) to the coupled REF experiment (not shown). The former shows significantly higher low cloud cover in the eastern and southeastern Tropical Atlantic. Even compared to the MOD experiment low cloud cover is higher in the REFUC experiment. The latter is due to the fact that a weak warm bias still exists in the MOD experiment.

So what drives the reduction of the eastern Tropical Atlantic SST bias in the MOD experiment? To further understand this, wind stress, precipitation and cloud cover at different levels in the REFUC as well as the MODUC experiment are analyzed. Differences in e.g. low cloud cover and precipitation in the eastern Tropical Atlantic in uncoupled (REFUC and MODUC) simulations relative to those in the REF experiment resemble those found for the MOD run. More specifically it is found that all configurations with correct SST show significantly higher low cloud cover in the southeastern Tropical Atlantic and stronger easterlies along the equator with respect to the REF experiment. However, only the MOD configuration maintains the mean state which is beneficial to the reduction of 
(a) REF - OBS

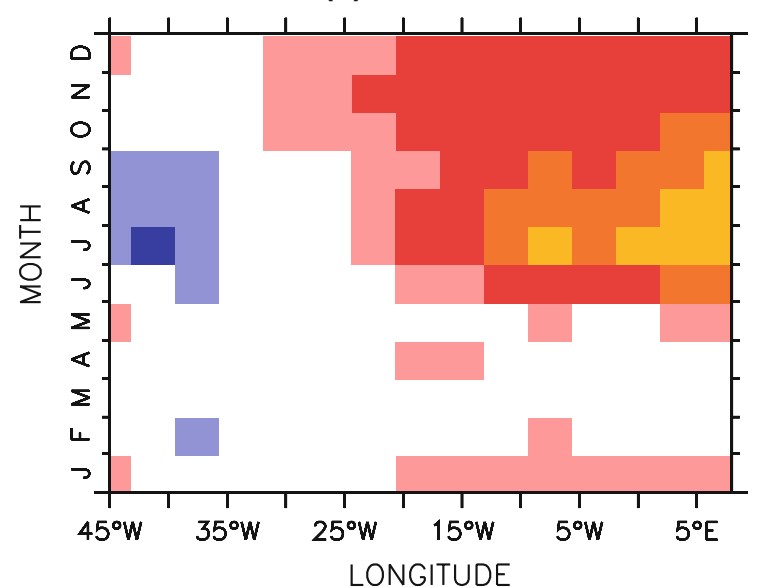

(b) MOD - OBS

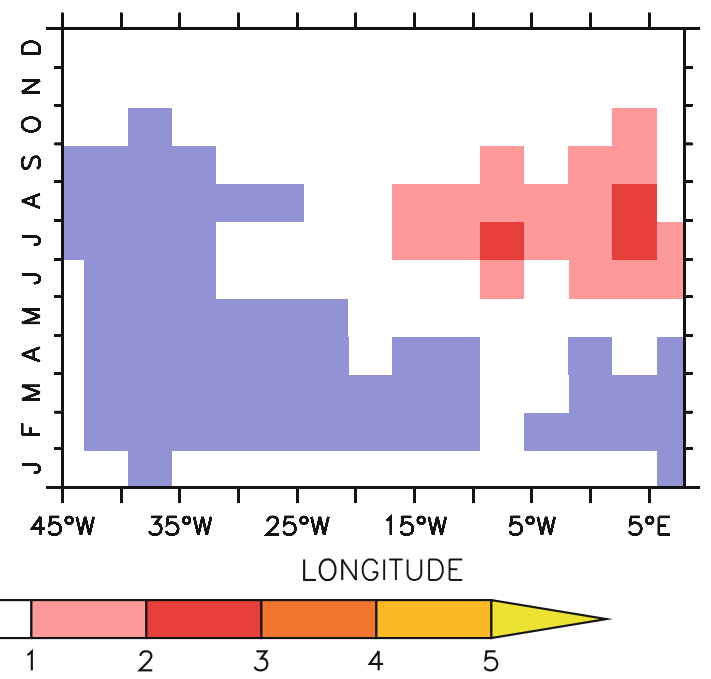

Fig. 7 Seasonal cycle of SST bias towards observations from a REF and $\mathbf{b}$ MOD configuration along the equator

the eastern Tropical Atlantic warm bias in coupled mode. It has to be pointed out that in the uncoupled runs the zonal wind stress component still contains errors with respect to observations, but they are smaller compared to what is seen in the coupled REF experiment. This is consistent with Richter and Xie (2008), who show that uncoupled models already contain biases in the Tropical Atlantic which amplify when run in coupled mode. From the comparison of the uncoupled (REFUC, MODUC) to the coupled (REF, MOD) experiments the following conclusions can be drawn: In the MODUC version of KCM the parameters which have been identified to be important for the reduction of the warm bias (spring easterlies along the equator, eastern and southeastern Tropical Atlantic low-level cloud cover, distribution of convection and associated precipitation patterns, etc.) have a stronger "signature", i.e. slightly stronger spring easterlies and increased low-level cloud cover in the eastern and southeastern Tropical Atlantic. Precipitation is strengthened especially east of $10^{\circ} \mathrm{W}$ compared to REFUC.

Nevertheless the key difference has to be in the modified treatment of surface exchange in the MOD as described in Sect. 2. We argue that stronger evaporation in the subtropical trade wind regions (Fig. 9) — caused by modifications in the MOD experiment-can be seen as a starting point for the processes leading to a reduction of the eastern Tropical Atlantic warm bias. In the MODUC experiment, the increase of latent heat (LH) flux is more evenly distributed in the Tropical and Subtropical Atlantic with respect to the REFUC experiment (Fig. 9a). The surface LH flux in the MOD experiment compared to the REF is primarily found in the western part of the Subtropics of both hemispheres. The additional availability of moisture enhances convection in the western Equatorial Atlantic driving stronger easterlies along the equator. This causes the thermocline to be closer to the surface in the east bringing colder water to the surface (Fig. 10f, see also next section). The surface cooling in the eastern Equatorial Atlantic reduces convection accordingly. Together with stronger convection in the west this corresponds to an intensified Walker Circulation along the equator. Colder surface water together with suppressed convection through changes in the Walker Circulation provides favorable conditions for the formation of low clouds. Increased amount of low cloud reduces surface shortwave radiation, which further contributes to colder SST. This mechanism is most effective in the southeastern Tropical Atlantic in late summer to fall. Although reduced, a significant warm SST bias remains directly along the southeastern coast between approximately $25^{\circ} \mathrm{S}$ and $10^{\circ} \mathrm{S}$ in all experiments. Weakerthan-observed southerly winds along the coast (present in all experiments but only shown for REF in Fig. 3) that can cause too weak coastal upwelling are one possible reason. Consistently, this bias is also present in the WIND4 and WIND10 experiments since correction of the wind field is only applied between $4^{\circ} \mathrm{S}\left(10^{\circ} \mathrm{S}\right)$ and $4^{\circ} \mathrm{N}\left(10^{\circ} \mathrm{N}\right)$ in these experiments.

\subsection{Ocean response}

In the following, changes in the ocean mean state and seasonal cycle in reaction to the various changes applied to the atmosphere shall be discussed. Figure 10 shows the 20-year mean temperature and salinity sections along the equator from the REF, WIND4, WIND10, RAD, FLX, MOD and OCE experiments as well as from SODA. The 

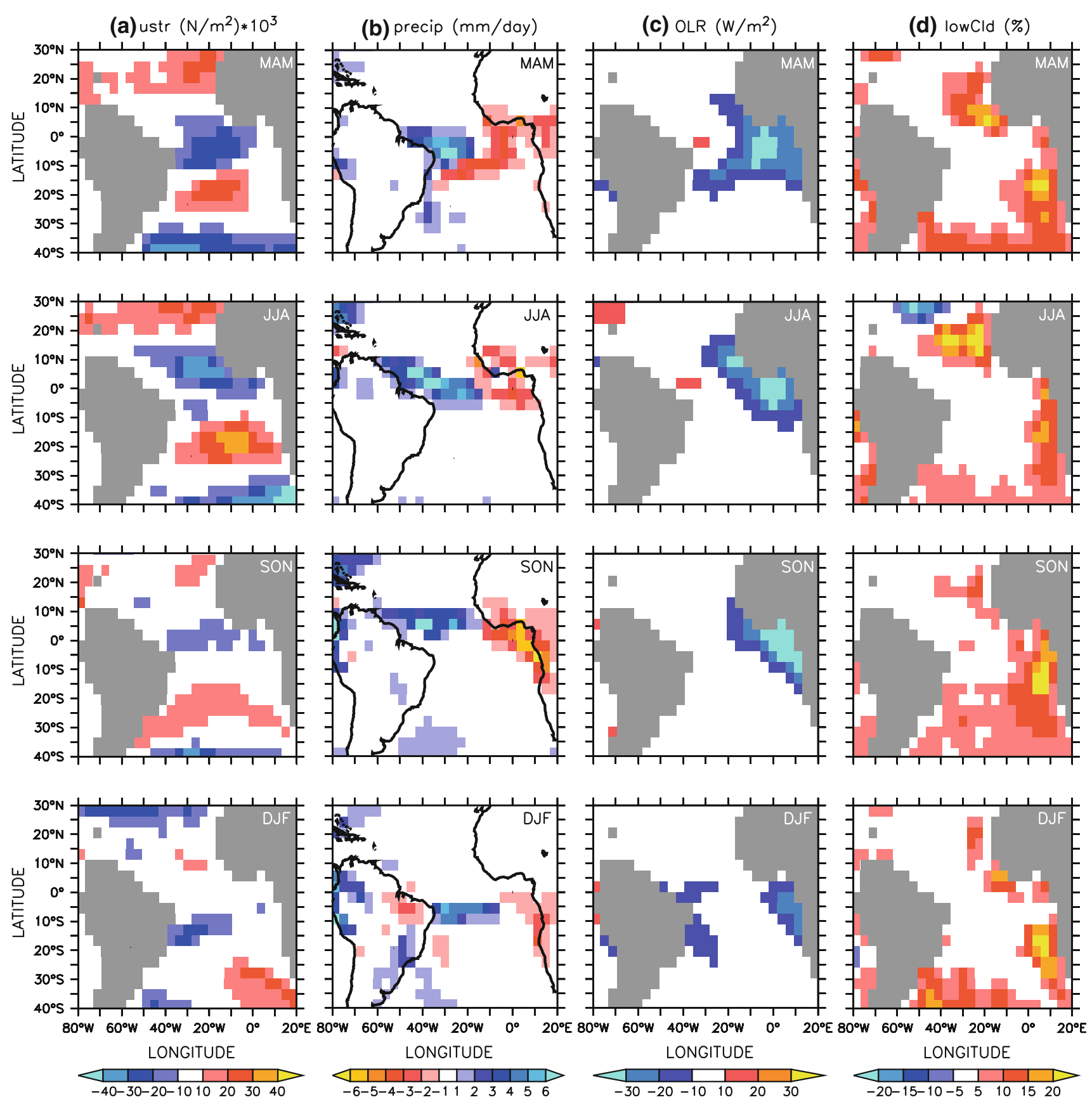

Fig. 8 MAM (top), JJA (second row), SON (third row) and DJF (bottom) of zonal wind stress (a), precipitation (b), OLR (c) and low cloud cover (d) differences between MOD and REF in the Tropical

Atlantic. Except for $\mathbf{b}$ values over land are not shown. Please note the reversed colorbar in $\mathbf{b}$

OCE experiment shows the most realistic tilt of the thermocline followed by the WIND4, FLX and RAD experiments. For the OCE and WIND4 experiments this is due to the realistic wind stress forcing. We also note that the WIND10 experiment has a thermocline tilt which is very similar to WIND4. In the FLX experiment the westerly wind stress bias at the equator is reduced (not shown) due to the fact that an amplification of the bias due to coupling (Richter and Xie 2008) is inhibited via the heat flux corrections towards the observed SST climatology. This results in an improved representation of the tilt of the thermocline. The RAD and MOD experiments still show a small bias in SST (Figs. 4, 6) and zonal winds along the equator that are improved with respect to the REF experiment, but still too weak compared to observations. The REF experiment has the strongest bias in zonal wind stress along the equator (Fig. 3b), and almost no tilt of the thermocline is simulated (Fig. 10a). Thus consistent with the 

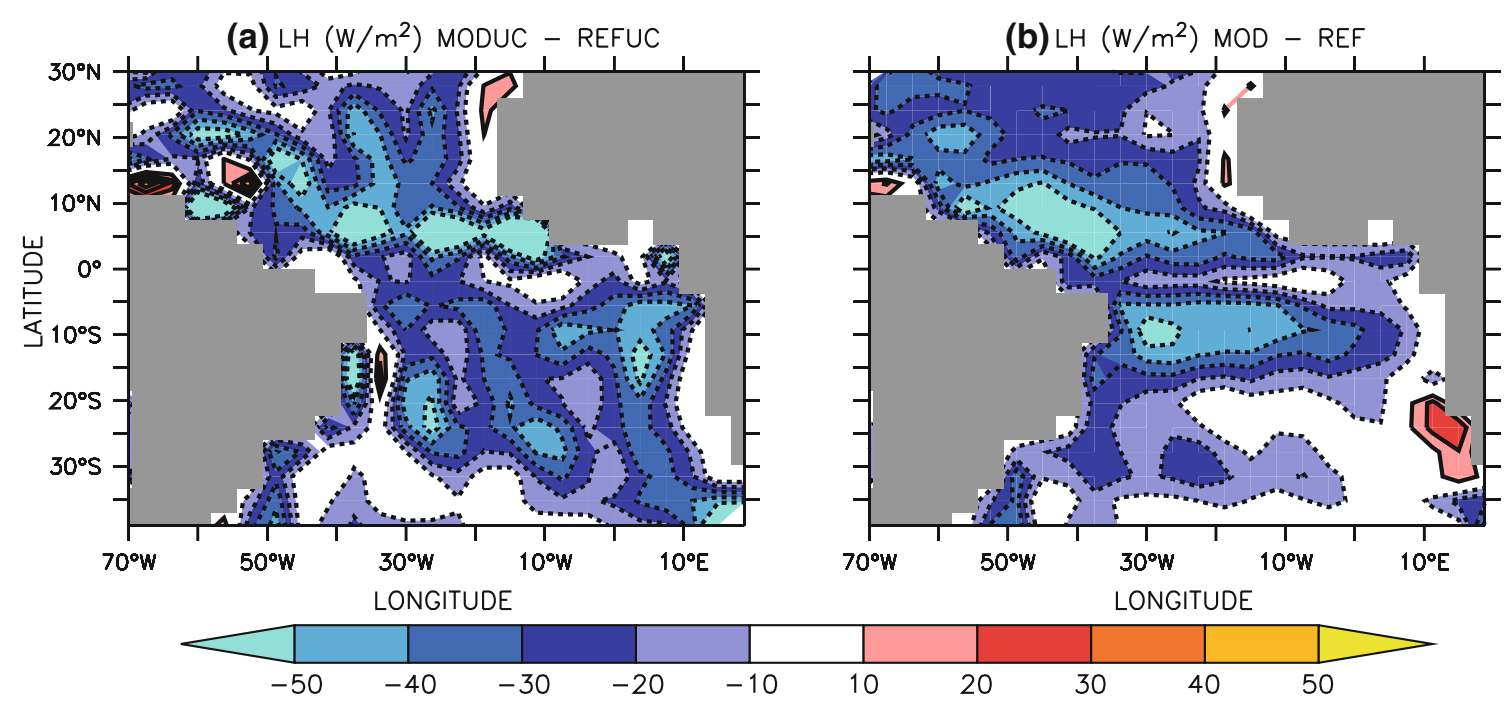

Fig. 9 Latent heat flux differences between the MODUC and REFUC (a) as well as the MOD and REF (b) experiment. Negative values denote higher latent heat flux from the ocean into the atmosphere in the MODUC and MOD experiment, respectively

theory of equatorial ocean dynamics, the representation of the tilt of the thermocline can hence, to first order, be related to the strength of the equatorial easterlies in the different experiments.

Surface salinities drop continuously towards the east and are below observed values in all levels in the upper $100 \mathrm{~m}$ in the REF run. At the surface this is consistent with too high precipitation compared to observations over the eastern Tropical Atlantic in the REF configuration all year round. In all configurations salinity increases with depth in the upper ocean, however, in the FLX run the increase is very weak. With respect to salinity the mixed layer is very shallow in the WIND4 experiment. The surface and subsurface salinity biases contribute to the seasonal development of surface and subsurface biases in temperature as discussed in the following.

The mean seasonal cycle of the depth of the $20^{\circ} \mathrm{C}$ isotherm for REF, MOD, WIND4, WIND10, FLX and OCE as well as observational estimates in the Atlantic 3 region (ATL3, $20^{\circ} \mathrm{W}-0^{\circ}, 3^{\circ} \mathrm{S}-3^{\circ} \mathrm{N}$ ) and a box in the eastern Equatorial Atlantic $\left(\mathrm{ETA}, 0^{\circ} \mathrm{E}-8^{\circ} \mathrm{E}, 2^{\circ} \mathrm{S}-2^{\circ} \mathrm{N}\right)$ is shown in Fig. 11 . The $20^{\circ} \mathrm{C}$ isotherm depth in the ETA box is shown as it is the region where the largest improvement in the SST bias is simulated in the MOD experiment. As expected the best representation of the seasonal cycle in the ATL3 region is found in the OCE experiment. The strength of the seasonal cycle is well captured, especially the minimum in $20^{\circ} \mathrm{C}$ depth in summer. In spring the $20^{\circ} \mathrm{C}$ isotherm is too deep. In the ETA region, the uncoupled ocean run (OCE) overestimates the strength of the seasonal cycle. Assuming that OCE experiment is the best in reproducing the mean seasonal cycle of the $20^{\circ} \mathrm{C}$ depth, the following comparison focuses on the differences with respect to the OCE run. In the WIND4 experiment the seasonal cycle is very weak. The WIND10 experiment has a seasonal cycle in $20^{\circ} \mathrm{C}$ isotherm depth that is nearly identical to the one found in the OCE experiment in the ATL3 region (Fig. 11). The differences between the WIND4 and WIND10 experiments indicate the importance of off-equatorial winds on the subsurface structure, but have not been studied further in detail.

In the REF experiment, the minimum in $20^{\circ} \mathrm{C}$ isotherm depth in summer is not simulated properly. Nevertheless, it is interesting that a seasonal cycle in $20^{\circ} \mathrm{C}$ isotherm depth (Fig. 11) in REF exists, in contrast to SST, which does not have a seasonal cycle at all (not shown). Therefore, the seasonal cycle in $20^{\circ} \mathrm{C}$ depth does not project onto the variations in SST. In conjunction with weaker than observed cross equatorial winds that cause weaker equatorial upwelling, this discrepancy might be related to the positive precipitation bias in the ETA that develops in spring and persists until late fall (Fig. 3d). As a consequence reduced surface salinities introduce a strong vertical salinity gradient preventing subsurface warming via the formation of an erroneous barrier layer (Breugem et al. 2008) at $20-30 \mathrm{~m}$ depth during boreal summer (not shown)). This causes a further warming of the surface layers enhancing the peak in the ETA warm bias from boreal summer to fall (Fig. 3a).

The representation of the seasonal cycle of the $20^{\circ} \mathrm{C}$ isotherm depth in the MOD experiment is improved, although $20^{\circ} \mathrm{C}$ isotherm depth is about $10 \mathrm{~m}$ closer to the surface in the annual mean (compare Fig. 10f and $10 \mathrm{~h}$ ). Both the unrealistic minimum in boreal winter and the 
(a) REF

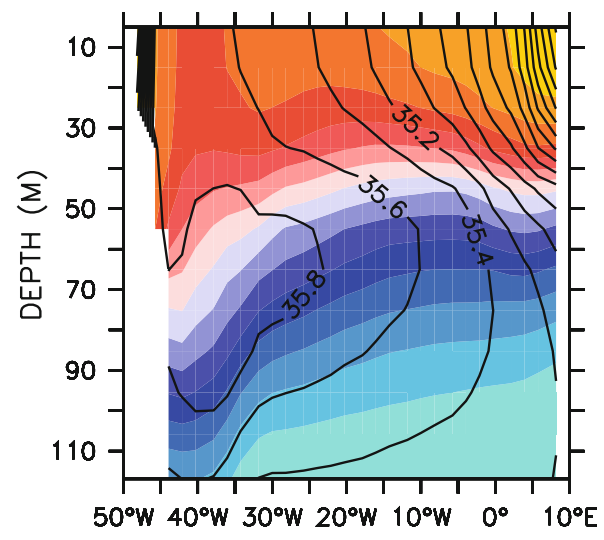

(d) RAD

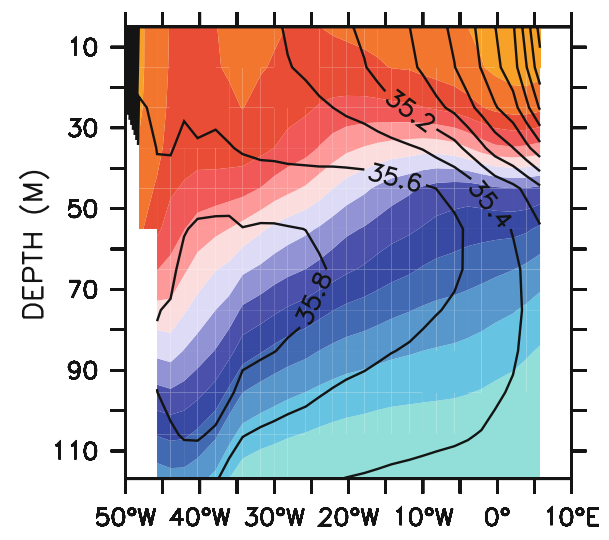

(g) OCE

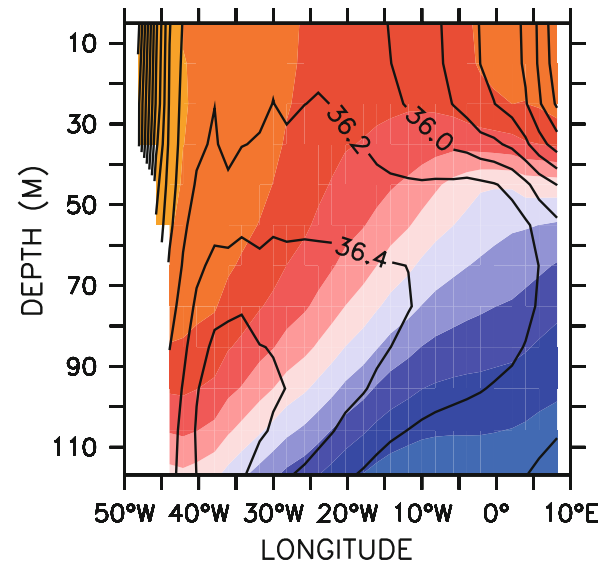

(b) WIND4

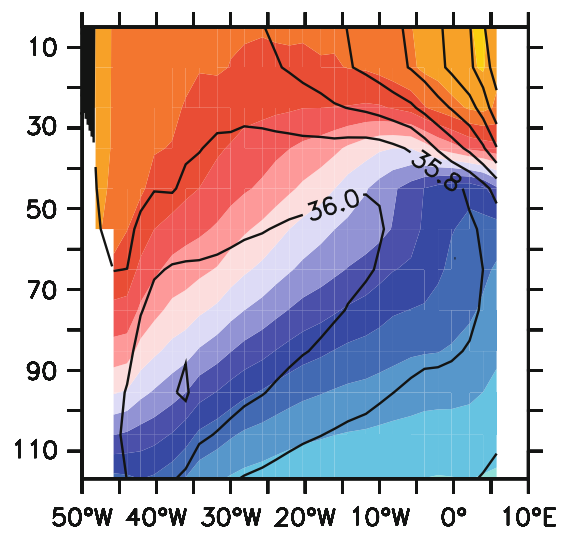

(e) $F L X$

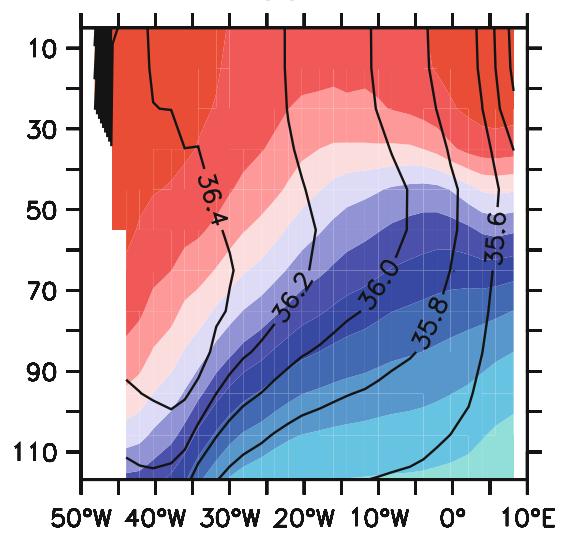

(h) SODA

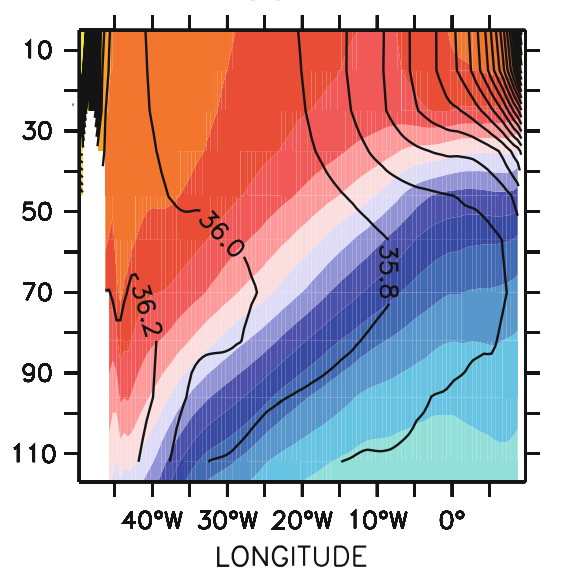

(c) WIND10

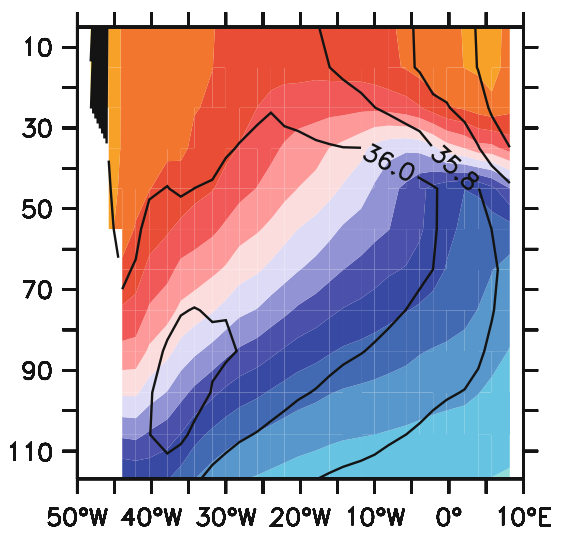

(f) $M O D$

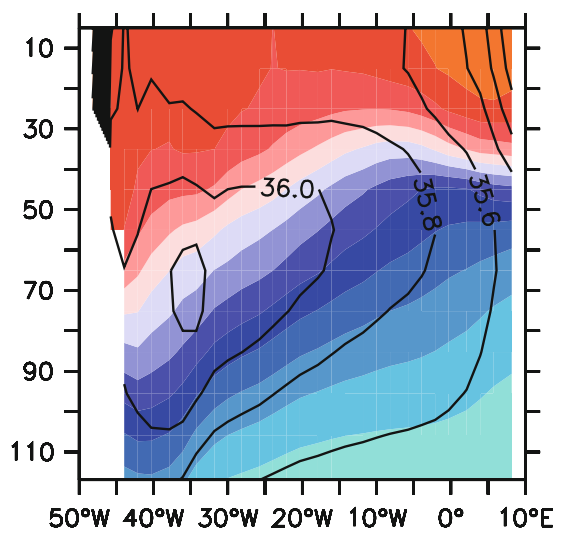

LONGITUDE

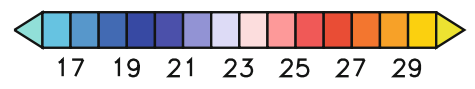

Fig. 10 Zonal section of sea water temperature (shading, ${ }^{\circ} \mathrm{C}$ ) and salinity (contours, psu) along the equator from REF (a), WIND4 (b), WIND10 (c), RAD (d), FLX (e), MOD (f) and OCE (g) experiment as well as the SODA dataset (h)

maximum in spring in REF are significantly reduced. Consistent with observations, a minimum in $20^{\circ} \mathrm{C}$ isotherm depth in the ATL3 region (and less pronounced in the ETA region) is found in the MOD experiment in boreal fall. Although the seasonal cycle in $20^{\circ} \mathrm{C}$ isotherm depth is caught, it is shifted by roughly 2 months. The improvements just described are primarily related to improved equatorial easterlies (Fig. 3). Reduced errors in the vertical salinity stratification in the eastern Equatorial Atlantic in the MOD experiment (Fig. 10f) possibly contribute to the reduction in the SST bias. The significant reduction of the precipitation bias especially in boreal fall (Fig. 8) reduces the surface and subsurface salinity bias. In the FLX experiment, the salinity stratification is very weak 
depth of $20 \mathrm{C}$ isotherm

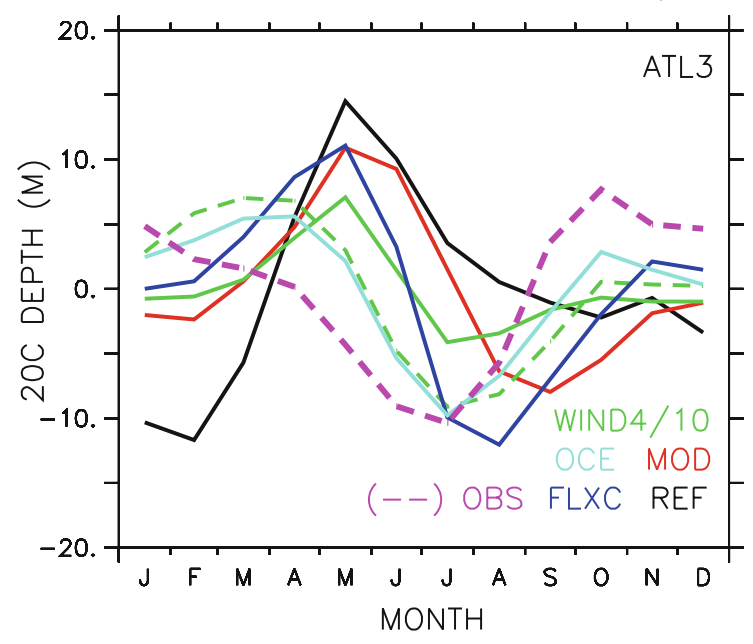

Fig. 11 Depth of $20^{\circ} \mathrm{C}$ isotherm (annual mean removed) for ATL3 $(l e f t)$ and ETA $(r i g h t)$ for various experiments as indicated on figure. Negative (positive) values denote a thermocline that is shallower

(Fig. 10e) due to the fact that no precipitation bias is present in the eastern Equatorial Atlantic (not shown). The correct surface temperatures imposed through the flux corrections can easily be distributed vertically causing possibly the stronger-than-observed subsurface temperature variations. In summary we find in accordance with the results by Breugem et al. (2008) that surface errors, specifically errors in freshwater flux in response to errors in precipitation, introduce errors in the vertical density stratification. Although the SST bias in the eastern Tropical Atlantic has shown to be primarily wind forced, errors in salinity stratification possibly amplify the SST bias in the eastern Tropical Atlantic. Correcting SST by implementing flux corrections hence does not provide a solution either as they cause a weaker-than-observed salinity stratification in the model. More sensitivity experiments (e.g. using freshwater flux corrections at the surface) are needed to finally quantify the relative importance of the erroneous barrier layers.

Although the focus of this work is on the Equatorial Atlantic, the wider impact of the modifications in the MOD experiment shall be discussed shortly. In the Pacific convection is intensified primarily over the western part of the basin resulting in precipitation that is above observed values. The significant warm biases that exist both off the Californian and Peruvian coast are reduced significantly, and consistent with the results for the Atlantic the amount of low cloud cover is increased.

\section{Conclusions}

This study brings together various aspects which have been claimed to be responsible for the strong warm bias in

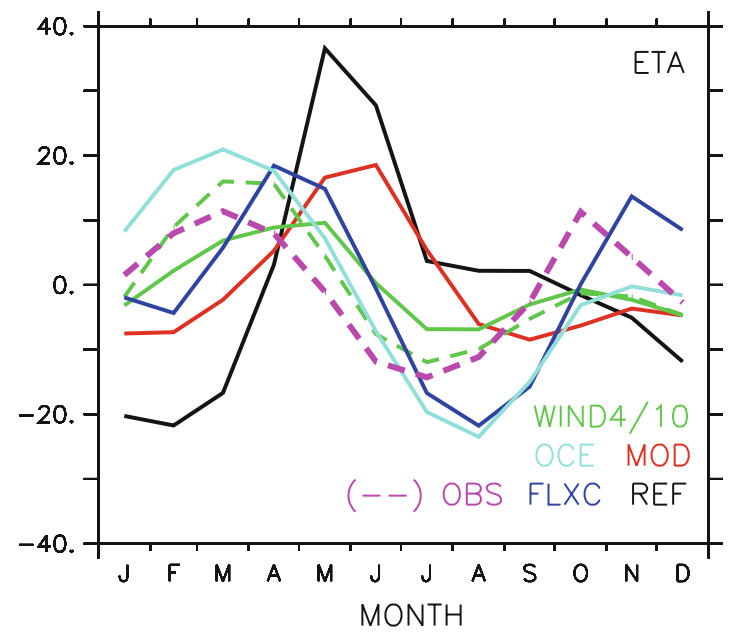

(deeper) than the annual mean. The solid (dashed) green line denotes the WIND4 (WIND10) experiment. Please note the different scale on the $y$-axis

the eastern Tropical Atlantic by comparing different configurations of the Kiel Climate Model (KCM). All previous studies discuss possible explanations for the evolution of the eastern Tropical Atlantic warm bias by comparing their erroneous (coupled) models to observations and/or the respective uncoupled model versions. By comparing sensitivity experiments and an (with respect to the warm bias) improved version of KCM with the standard version, this paper highlights the major problems in coupled Tropical Atlantic climate modeling from a different perspective.

It turns out that the eastern Tropical Atlantic warm bias and the associated error in the zonal SST gradient along the equator are related to two mechanisms:

1) For the wrong zonal gradient and the equatorial warm bias, the error in the spring and early summer zonal winds associated with erroneous zonal precipitation distribution as discussed by e.g. Richter and Xie (2008) seems to be the key mechanism. Improved winds in boreal spring cause the summer cooling in the eastern Tropical Atlantic via shoaling of the thermocline and increased upwelling. Reduced SSTs in the summer suppress convection and favor the development of low-level cloud cover in the ETA region through stabilization of the lower troposphere. Outgoing longwave radiation is largely increased through the reduction of high cloud due to cirrus spreading from convective towers. Indications are given showing that the development of erroneous barrier layers (Breugem et al. 2008) might contribute to the rapid strengthening of the SST bias in boreal summer as well as the large errors in thermocline structure. 
2) The strong warm bias along the southeastern coastline is related to underestimation of low-level cloud cover and the associated overestimation of surface shortwave radiation in the same region which has also been mentioned by Huang et al. (2007). Especially south of the equator along the African coastline, low-level cloud cover increases in the MOD experiment. The largest improvements are found from summer to fall. This coincides with the largest reduction of SST in that region and the time period where low-level cloud cover and SST show the strongest correlation, indicating that the amount of low cloud is also forced by SST. So in addition to the primarily wind forced response at the equator, both changes in surface shortwave radiation and OLR contribute significantly to reduction of the warm bias from summer to fall. Supported by the WIND4, WIND10 and RAD sensitivity experiments it has been shown that both mechanisms need to be present to effectively reduce the eastern Tropical Atlantic warm bias. Weaker-than-observed southerly winds along the southeastern coast, which are present in all experiments, could be responsible for the local bias, which is still present along the southeastern coast, but needs further study.

A limitation of our results could be the low model resolution used, and therefore processes that can contribute to the reduction of the bias might be missing (e.g. weaker than observed coastal upwelling). Nevertheless, similar bias patterns in the Tropical Atlantic are also present in higher resolution coupled models (e.g. Hu et al. 2008).

To successfully model Tropical Atlantic climate, convection over northeastern Brazil seems to be one key parameter as it is at the heart of the feedback chain discussed in this paper. The modifications applied in the model improve the east-west structure in precipitation. Yet they fail to correctly place the surplus of convective activity over land. The key issue of future model development with respect to the tropical climate in KCM should therefore be the improved representation of land convection over northeastern Brazil, without destroying the quite realistic representation of other important climate features such as ENSO in the model.

Acknowledgments The authors thank J.-J. Luo for the discussion of the bias problem in CGCMs that provided good ideas for this study. We also would like to thank A. Biastoch for providing the forced ocean run data as well as the input of two reviewers that helped to improve the manuscript. The authors wish to acknowledge use of the Ferret program for analysis and graphics in this paper. This work was supported by the Nordatlantik project of BMBF and the AMMA project of the European Union.

\section{References}

Breugem W-P, Chang P, Jang CJ, Mignot J, Hazeleger W (2008) Barrier layers and Tropical Atlantic SST biases in coupled GCMs. Tellus A 60(5):885-897

Carton JA, Giese BS (2008) A reanalysis of ocean climate using simple ocean data assimilation (SODA). Mon Wea Rev 136(8):2999-3017

Chang C-Y, Carton JA, Grodsky SA, Nigam S (2007) Seasonal climate of the Tropical Atlantic sector in the NCAR community climate system model 3: error structure and probable causes of errors. J Clim 20:1053-1070

Chang C-Y, Nigam S, Carton JA (2008) Origin of the springtime westerly bias in equatorial atlantic surface winds in the community atmosphere model version 3 (CAM3) simulation. J Clim 21(18):4766-4778

Collins W, Bitz C, Blackmon M, Bonan G, Bretherton C, Carton J, Chang P, Doney S, Hack J, Henderson T, Kiehl J, Large W, McKenna D, Santer B, Smith R (2006) The community climate system model version 3 (CCSM3). J Clim 19:2122-2143

Davey MK, Huddleston M, Sperber K, Braconnot P, Bryan F, Chen D, Colman R, Cooper C, Cubasch U, Delecluse P, DeWitt D, Fairhead L, Flato G, Gordon C, Hogan T, Ji M, Kimoto M, Kitoh A, Knutson T, Latif M, Treut HL, Li T, Manabe S, Mechoso C, Meehl G, Power S, Roeckner E, Terray L, Vintzileos A, Voss R, Wang B, Washington W, Yoshikawa I, Yu J, Yukimoto S, Zebiak S (2002) STOIC: a study of coupled model climatology and variability in tropical ocean regions. Clim Dyn 18:403-420

Ding H, Keenlyside N, Latif M (2009) Seasonal cycle in the upper Equatorial Atlantic Ocean. J Geophys Res 114(C9):C09016

Florenchie P, Lutjeharms JRE, Reason CJC, Masson S, Rouault M (2003) The source of Benguela Ninos in the South Atlantic Ocean. Geophys Res Lett 30(10):1505

Fu R, Genio AD, Rossow WB (1994) Influence of ocean surface conditions on atmospheric vertical thermodynamic structure and deep convection. J Clim 7:1092-1108

Gates WL (1992) AMIP: the atmospheric model intercomparison project. Bull Am Meteor Soc 73(12):1962-1970

Gordon CT, Rosati A, Gudgel R (2000) Tropical sensitivity of a coupled model to specified ISCCP low clouds. J Clim 13:22392260

Graf J, Sasaki C, Winn C, Liu WT, Tsai W (1998) NASA scatterometer experiment. Acta Astronaut 7-8:397-407

Hazeleger W, Haarsma R (2005) Sensitivity of Tropical Atlantic climate to mixing in a coupled ocean-atmosphere model. Clim Dyn 25(4):387-399

$\mathrm{Hu}$ Z, Huang B (2007) Physical processes associated with the Tropical Atlantic SST gradient during the anomalous evolution in the southeastern ocean. J Clim 20:3366-3378

Hu Z-Z, Huang B, Pegion K (2008) Low cloud error over the southeastern atlantic in the NCEP CFS and their association with lower-tropospheric stability and air-sea interaction. J Geophys Res 113:D12114

Huang B, Hu Z-Z, Jha B (2007) Evolution of model systematic errors in the Tropical Atlantic basin from coupled climate hindcasts. Clim Dyn 28(7-8):661-682

Hulme M, Doherty R, Ngara T, New M, Lister D (2001) African climate change: 1900-2100. Clim Res 17:145-168

Kalnay E, Kanamitsu M, Kistler R et al (1996) The NCEP/NCAR 40-year reanalysis project. Bull Am Meteor Soc 77:437-470

Kara AB, Rochford PA, Hurlburt HE (2000) Efficient and accurate bulk parameterizations of air-sea fluxes for use in general circulation models. J Atmos Ocean Technol 17(10):1421-1438

Large WG, Danabasoglu G (2006) Attribution and impacts of upperocean biases in CCSM3. J Clim 19:2325-2346 
Latif M, Park W, Ding H, Keenlyside N (2009) Internal and external north atlantic sector variability in the Kiel Climate Model. Meteor Z (accepted)

Lee S-K, Wang C (2008) Tropical Atlantic decadal oscillation and its potential impact on the equatorial atmosphere ocean dynamics: a simple model study. J Phys Oceanogr 38(1):192-212

Ma C, Mechoso C, Robertson A, Arakawa A (1996) Peruvian stratus clouds and the tropical pacific circulation: a coupled oceanatmosphere GCM study. J Clim 9:1635-1645

Madec G (2008) NEMO ocean engine. Note du Pole de modelisation, Institut Pierre-Simon Laplace (IPSL) No 27. ISSN No 12881619

Miller M, Beljaars A, Palmer T (1992) The sensitivitiy of the ECMWF model to parameterization of evaporation from the tropical oceans. J Clim 5:418-434

Nigam S (1997) The annual warm to cold phase transition in the eastern equatorial pacific: diagnosis of the role of stratus cloudtop cooling. J Clim 10:2447-2467

Park W, Latif M (2008) Multidecadal and multicentennial variability of the meridional overturning circulation. Geophys Res Lett 35:L22703

Park W, Keenlyside N, Latif M, Stroeh A, Redler R, Roeckner E, Madec G (2009) Tropical pacific climate and its response to global warming in the Kiel Climate Model. J Clim 22:71-92

Polo I, Lazar A, Rodriguez-Fonseca B, Arnault S (2008) Oceanic Kelvin waves and Tropical Atlantic intraseasonal variability: 1 . Kelvin wave characterization. J Geophys Res 113:C07009

Richter I, Xie S-P (2008) On the origin of equatorial atlantic biases in coupled general circulation models. Clim Dyn 31(5):587-598
Roeckner E, Bäuml G, Bonaventura L, Brokopf R, Esch M, Girogetta M, Hagemann S, Kirchner I, Kornblueh L, Manzini E, Rhodin A, Schlese U, Schulzweida U, Tompkins A (2003) The atmospheric general circulation model ECHAM 5, Part I, MPI Report 349:137p. Max-Planck-Institut für Meteorologie, Hamburg

Rossow WB, Schiffer RA (1991) ISCCP cloud data products. Bull Am Meteor Soc 72(1):2-20

Saha S, Nadiga S, Thiaw C, Wang J, Wang W, Zhang Q, Van den Dool HM, Pan HL, Moorthi S, Behringer D, Stokes D, Pena M, Lord S, White G, Ebisuzaki W, Peng P, Xie P (2006) The NCEP climate forecast system. J Clim 19(15):3483-3517

Seo H, Jochum M, Murtugudde R, Miller A (2006) Effect of ocean mesoscale variability on the mean state of Tropical Atlantic climate. Geophys Res Lett 33:L0960

Servain J (1991) Simple climatic indices for the Tropical Atlantic ocean and some applications. J Geophys Res 96(C8):1513715146

Stockdale TN, Balmaseda M, Vidard A (2006) Tropical Atlantic SST prediction with coupled ocean-atmosphere GCMs. J Clim 19:6047-6061

Valcke S, Guilyardi E, Larsson C (2006) PRISM and ENES: a European approach to earth system modelling. Concurrency Comput Pract Expert 18(2):231-245

Xie P, Arkin P (1997) Global precipitation: a 17-year monthly analysis based on gauge observations, satellite estimates, and numerical model outputs. Bull Am Meteor Soc 78(11):25392558

Yu J-Y, Mechoso CR (1999) A discussion on the errors in the surface heat fluxes simulated by a coupled GCMs. J Clim 12:416-426 